\title{
Lessons of the month: Pyroglutamic acidosis: long-term paracetamol and a high anion gap
}

\author{
Authors: Emma Trevor-Jones, ${ }^{\mathrm{A}}$ Lewis T Hughes, ${ }^{\mathrm{B}}$ Rebecca Robson, ${ }^{\mathrm{C}}$ Alan Bromley ${ }^{\mathrm{D}}$ and Gordon W Stewart ${ }^{\mathrm{E}}$
}

\begin{abstract}
An 84-year-old woman presented in extremis with confusion and Kussmaul respiration. She had a history of urosepsis, renal impairment and osteoarthrosis. The venous blood gas showed a marked metabolic acidosis with a high anion gap. Lactate and ketones were normal. Her medications included regular paracetamol via a dosette box. Lactic acidosis and ketoacidosis being excluded, it emerged that the most likely cause of a high anion-gap acidosis in the presence of chronic paracetamol therapy is pyroglutamic acidosis, caused by the build-up of an acidic intermediate in the gamma-glutamyl cycle, the function of which is to synthesise glutathione. Paracetamol was stopped and fluids administered; she recovered over 7 days and was sent home. The biochemical diagnosis was confirmed by a central laboratory after discharge. This case emphasises the importance of the anion gap in diagnosis, and one important danger of chronic paracetamol administration.
\end{abstract}

KEYWORDS: Pyroglutamic acidosis, paracetamol, anion gap

DOI: $10.7861 /$ clinmed.2020-0363

\section{Introduction}

The anion gap (the difference between the easily measurable cations and easily measurable anions) remains a difficult idea for many doctors, but it can be very important. This case illustrates this point.

\section{Case presentation}

In a remote island hospital, an 84-year-old woman presented with a 1-day history of confusion and distressing breathlessness. Her background included chronic kidney disease stage 3b, paroxysmal atrial fibrillation, asthma and osteoarthritis with associated poor mobility. She had had a recent admission with Escherichia coli

Authors: Alocum doctor in medicine, Western Isles Hospital, Stornoway, UK; ${ }^{B}$ speciality doctor in palliative and supportive care, Western Isles Hospital, Stornoway, UK; ${ }^{C}$ speciality trainee in general practice, Western Isles Hospital, Stornoway, UK; ${ }^{\text {D }}$ senior biomedical scientist, Western Isles Hospital, Stornoway, UK; ${ }^{{ }}$consultant physician, Western Isles Hospital, Stornoway, UK

urosepsis. Her regular medications, administered via a dosette box, included quetiapine $25 \mathrm{mg}$ two tabs twice a day (bd); paracetamol $1 \mathrm{~g}$ four times a day; omeprazole $20 \mathrm{mg}$ every morning (om); mirtazapine $45 \mathrm{mg}$ at night; furosemide $40 \mathrm{mg}$ om; digoxin $62.5 \mathrm{\mu g}$ om; bisoprolol $2.5 \mathrm{mg}$ om; and apixaban $2.5 \mathrm{mg}$ bd.

On examination, she was in distress with classic deep, rapid Kussmaul respiration at a respiratory rate of 22 breaths/min. Her oxygen saturation on room air was $97 \%$. Her pulse rate was 122 beats/min and blood pressure was 142/60 mmHg. Her temperature was $37.3^{\circ} \mathrm{C}$. She was disorientated with a $4 A T$ delirium screen of 8 out of 12 (a score of greater than 4 suggests delirium and/or cognitive impairment). The heart sounds were normal and the chest was clear on auscultation. There was mild generalised tenderness in the abdomen, with normal bowel sounds; there were no focal neurological signs.

Admission blood tests are shown in Table 1. The initial venous gas showed a pH of 7.11, partial pressure of carbon dioxide of

Table 1. Admission biochemical blood test data

Measurement

$\mathrm{pH}$

$\mathrm{pO}_{2}$

$\mathrm{pCO}_{2}$

Base excess

Bicarbonate

Sodium

Potassium

Chloride

Ionised calcium

Glucose

Lactate

Ketones

Anion gap

Creatinine

eGFR

Urea

eGFR $=$ estimated glomerular filtration rate; $\mathrm{pCO}_{2}=$ partial pressure of carbon dioxide; $\mathrm{pO}_{2}=$ partial pressure of oxygen.
Value (normal range)

$7.11(7.35-7.45)$

$9.4 \mathrm{kPa}(11.1-14.4)$

$2.6 \mathrm{kPa}(4.3-6.0)$

$-23.3 \mathrm{mmol} / \mathrm{L}(-2.0-+2.0)$

$9.1 \mathrm{mmol} / \mathrm{L}(21-28)$

$145 \mathrm{mmol} / \mathrm{L}(133-146)$

$3.9 \mathrm{mmol} / \mathrm{L}(3.5-5.0)$

$114 \mathrm{mmol} / \mathrm{L}(95-108)$

$1.11 \mathrm{mmol} / \mathrm{L}(1.15-1.29)$

$8.1 \mathrm{mmol} / \mathrm{L}(3.5-5.0)$

$1.2 \mathrm{mmol} / \mathrm{L}(0.5-1.6)$

$2.1 \mathrm{mmol} / \mathrm{L}(<0.6)$

$21.9 \mathrm{mmol} / \mathrm{L}(6-12)$

$309 \mu \mathrm{mol} / \mathrm{L}(4-120)$

$15.3 \mathrm{~mL} / \mathrm{min}(>60)$

$17.9 \mathrm{mmol} / \mathrm{L}(3.5-7.2)$ 
$2.6 \mathrm{kPa}$, bicarbonate of $9.1 \mathrm{mmol} / \mathrm{L}$, base excess of $-23.3 \mathrm{mmol} / \mathrm{L}$, lactate of $1.3 \mathrm{mmol} / \mathrm{L}$ and ketones of $2.1 \mathrm{mmol} / \mathrm{L}$. Although the ketone level was on the high side, in frank ketoacidosis the level usually exceeds $3.0 \mathrm{mmol} / \mathrm{L}$. Her calculated anion gap $\left(\mathrm{Na}^{+}-\mathrm{Cl}^{-}-\mathrm{HCO}_{3}{ }^{-}\right.$) was $21.9 \mathrm{mmol} / \mathrm{L}$ (normal range 6-12). ${ }^{1}$ Her blood glucose was $8.1 \mathrm{mmol} / \mathrm{L}$. Renal tests showed an acute kidney injury (estimated glomerular filtration rate $15.3 \mathrm{~mL} / \mathrm{min}$ against a baseline of $32 \mathrm{~mL} / \mathrm{min}$ ). Her potassium was not high at $3.9 \mathrm{mmol} / \mathrm{L}$. Her blood count showed a total white cell count of $21 \times 10^{9} / \mathrm{L}$ with a neutrophilia of $20 \times 10^{9} / \mathrm{L}$, haemoglobin of $93 \mathrm{~g} / \mathrm{L}$. Her C-reactive protein was raised at $128.93 \mathrm{mg} / \mathrm{L}$. When catheterised, a quantity of offensive cloudy urine was drained. A contrast computed tomography of the chest, abdomen and pelvis was normal.

Given the patient's past history and urine, a working diagnosis of urosepsis was made. Initial management included empirical intravenous antibiotics (levofloxacin and gentamicin). Fluids were administered.

The acidosis remained unexplained. A key point was that the anion gap was clearly large, very strongly suggesting that present in the blood was an excess of some kind of organic acid, which was (by virtue of our very useful point-of-care tests) neither lactate nor ketones.

The possibility of a drug cause among her multiple medications was entertained. Internet searching at first suggested quetiapine, which can give diabetic ketoacidosis, but the blood glucose was not high and the ketones were also not sufficiently high. ${ }^{2}$ To the surprise of the clinical team, the very widely-used analgesic, paracetamol, emerged as a possible cause. It is recognised that even in therapeutic doses and with therapeutic blood levels, high anion-gap metabolic acidosis can occur in chronic paracetamol treatment, due to accumulation in the blood of an amino acid known as 'pyroglutamate.' 3

Pyroglutamic acidosis was therefore a diagnostic possibility in this case. The patient was on the paracetamol and other potential contributory factors which can contribute to pyroglutamic acidosis were present in this case: sepsis, renal impairment and female gender. There was no other obvious cause, such as ingestion of a toxic alcohol. Pyroglutamic acidosis was adopted as the running diagnosis, the paracetamol was stopped, fluids and precautionary $\mathrm{N}$-acetyl cysteine were given. Over the course of a week, she gradually improved and was discharged well, after 8 days in the hospital. After her discharge, the urinary pyroglutamate level was reported by the mainland lab to be about $800 \mu \mathrm{g} / \mathrm{mg}$ creatinine (the normal upper limit is about $38 \mu \mathrm{g} / \mathrm{mg}$ creatinine), thus confirming the clinical diagnosis.

\section{Discussion}

Pyroglutamate is a derivative of glutamate and is involved in a cyclic pathway (the 'gamma-glutamyl cycle') which makes glutathione. The relevance here is that glutathione is irreversibly damaged by a metabolite of paracetamol, N-acetylp-benzoquinone imine (NAPQI). ${ }^{4}$ As first shown by Pitt and colleagues, it can happen that in chronic therapeutic paracetamol administration, and in the presence of other factors, the cycle can be disrupted, with abnormal accumulation of pyroglutamate and the development of a consequent high anion-gap metabolic acidosis. ${ }^{5,6}$ The 'other factors' include renal failure, infection and female gender (present here); and others including poor nutrition, strict vegetarianism, chronic alcohol use, pregnancy, and treatment with flucloxacillin, netilmicin and dabigatran (none of which applied here). ${ }^{3}$

The gamma-glutamyl cycle is a complex piece of biochemistry. The whole background, including the basic biochemistry, the typical clinical scenarios, the use of the anion gap, and the management options, which can include dialysis, is very well described by Hunter and colleagues. ${ }^{3}$

For unknown reasons, the potassium level in serum is lower in pyroglutamic acidosis then would be expected for the $\mathrm{pH}$, as was the case here. Our patient was on furosemide, but the potassium is not high in typical cases where there is no such possible contributing factor. ${ }^{3}$

For us, the lessons of this case are:

> it was the calculation and assessment of the anion gap which made us search for the diagnosis

> pyroglutamic acidosis is a rare but easily-treatable cause of high anion-gap metabolic acidosis, and can be a life-threatening complication of therapeutic paracetamol prescription in certain clinical contexts

> readily available ketones and lactate assays to evaluate causes of high anion-gap metabolic acidosis, as well as strong clinical suspicion, is enough to strongly suspect pyroglutamic acidosis even in remote and rural settings.

Finally, the term 'gamma-glutamyl' is familiar on the wards. It is part of everyday clinical parlance, because the initials 'GGT' stand for 'gamma-glutamyl transferase', a membrane-bound enzyme which is part of the gamma-glutamyl cycle, but which is not directly involved in pyroglutamic acidosis. ${ }^{7}$

\section{Acknowledgements}

We thank the patient for her consent to publish this report, and the specialised metabolic investigations lab in Glasgow for the pyroglutamate measurements.

\section{References}

1 Berend K, de Vries AP, Gans RO. Physiological approach to assessment of acid-base disturbances. N Engl J Med 2014;371:1434-45.

2 Sobel M, Jaggers ED, Franz MA. New-onset diabetes mellitus associated with the initiation of quetiapine treatment. J Clin Psychiatry 1999;60:556-7.

3 Hunter RW, Lawson C, Galitsiou E et al. Pyroglutamic acidosis in association with therapeutic paracetamol use. Clin Med 2016;16: 524-9.

4 Mitchell JR, Jollow DJ, Potter WZ et al. Acetaminophen-induced hepatic necrosis. IV. Protective role of glutathione. J Pharmacol Exp Ther 1973;187:211-7.

5 Pitt ]. Association between paracetamol and pyroglutamic aciduria. Clin Chem 1990;36:173-4.

6 Pitt J], Brown GK, Clift V, Christodoulou J. Atypical pyroglutamic aciduria: possible role of paracetamol. J Inherit Metab Dis 1990;13: 755-6.

7 Emmett M. Acetaminophen toxicity and 5-oxoproline (pyroglutamic acid): a tale of two cycles, one an ATP-depleting futile cycle and the other a useful cycle. Clin J Am Soc Nephrol 2014;9:191-200.

Address for correspondence: Dr Gordon W Stewart, Western Isles Hospital, Macaulay Road, Stornoway, Isle of Lewis HS1 2NB, UK.

Email: g.stewart4@nhs.net 